\title{
Novel Ductile FRP System for Concrete Reinforcement: Concept and Experimental Characterization
}

\author{
Wei Sun ${ }^{1}$, Haifeng Liu ${ }^{2}$, Mithila Achintha ${ }^{3}$, Chunlin $\mathrm{Pan}^{4}$, Tao $\mathrm{He}^{5}$ \\ ${ }^{1}$ Associate Professor, Key Laboratory of Ministry of Education for Mechanics on Western Disaster and \\ Environment, School of Civil Engineering and Mechanics, Lanzhou Univ., Lanzhou 730000, China \\ (corresponding author) Email: wsun@1zu.edu.cn; Wei.Sun@ soton.ac.uk \\ ${ }^{2}$ Graduate Student, Key Laboratory of Ministry of Education for Mechanics on Western Disaster and \\ Environment, School of Civil Engineering and Mechanics, Lanzhou Univ., Lanzhou 730000, China \\ ${ }^{3}$ Lecturer, Engineering and the Environment, Univ. of Southampton, Highfield, Southampton, SO17 1BJ, \\ U.K. \\ ${ }^{4}$ Associate Professor, Key Laboratory of Ministry of Education for Mechanics on Western Disaster and \\ Environment, School of Civil Engineering and Mechanics, Lanzhou Univ., Lanzhou 730000, China \\ ${ }^{5}$ Graduate Student, Key Laboratory of Ministry of Education for Mechanics on Western Disaster and \\ Environment, School of Civil Engineering and Mechanics, Lanzhou Univ., Lanzhou 730000, China
}

\section{Abstract}

This paper presents a novel design concept for fiber reinforced polymer (FRP) composites consisting of three-dimensional (3D) printed cores and FRP helical skins as a means of ensuring adequate ductility, compared to the brittle FRP systems conventionally used for internal reinforcement. The experiment demonstrated that when the FRP skins were loaded in tension, the core-which was 3D printed using acrylonitrile butadiene styrene or polylactic acid—was gradually compressed, thereby leading to plastic deformation. This behavior ensured a nonlinear load response while eliminating the unfavorable brittle failure of the FRPs. The results also indicated that the proposed FRP composite system ensured that no premature debonding/delamination occurred between the skin-skin and skin-core. The results of the parametric experimental study indicated that design parameters such as the FRP amount, core height, core span, core shell thickness, core material, core brace, and core number (i.e., the number of inner cores used for the composite) may be optimized to realize the expected design load capacity and ductility.

Keywords: 3D-print; ABS core; PLA core; Ductility; FRP; Nonlinear; Strength 
Corrosion of steel in reinforced concrete causes concrete cracking, loss of bond strength, reduction in the

steel cross section, and loss of serviceability (Cabrera 1996). It has been reported that the corrosion of steel

in reinforced concrete $(\mathrm{RC})$ requires over $\$ 8$ billion annually for repairing $\mathrm{RC}$ bridges in the United States

(Behnam and Eamon 2013; US Federal Highway Administration 2001). Although the corrosion of steel in

RC may be treated by improving the concrete mix design, increasing the thickness of the concrete cover

(Faustino et al. 2015), and employing cathodic protection and epoxy-coating methods, such methods fail to

completely eliminate the corrosion.

Over the last few decades, the use of FRP as reinforcement in concrete members has gained interest among

the researchers and designers owing to the corrosion resistance, high strength and low-weight characteristics

of the materials. (Achintha et al. 2018; Achintha M 2009; Lou et al. 2016, 2017a; b; Lou and Karavasilis

2018; Sun et al. 2017a, 2018; Sun 2018; Sun et al. 2016, 2017b; Sun and Ghannoum 2015). Despite FRPs

together with its long-term benefits such as low maintenance and high durability may enable FRP

reinforcement systems to be a viable alternative to steel reinforcement. Nevertheless, the brittle failure and

premature debonding of the material when used as reinforcement in concrete has limited the more widespread

in some applications, the ductility of the FRP reinforced concrete systems needed to be improved. The use of stainless steel fibers was noted to enhance the ductility (Allaer et al. 2014); however, the relatively high density of steel led to limitations, in particular, in lightweight applications. 
laminates can realize pseudoductility by stably pulling the low strain material out of the composite (Czél et al. 2017; Czél and Wisnom 2013; Jalalvand et al. 2015). However, the ductile behavior significantly depends on the interfacial bond (Jalalvand et al. 2015), which might be degraded under the effects of UV light (Zhai et al. 2016) and/or heat (Mohan 2013) in the field. Other approaches involved providing fibers with excess length for developing further extensions. Possible solutions to produce such excess lengths involved fabricating fabrics with diagonally oriented fibers (Grace et al. 2004) or corrugated fibers (Yokozeki et al. 2006), which could be re-oriented or unfolded to produce further extensions in the process of adapting to the loading direction. However, these fabrics required adequate matrices to resist the fiber rotation; otherwise, significant deformations could be developed on the initiation of loading, thereby torpedoing the candidacy of the fabrics to replace steel reinforcements.

More sophisticated approaches to ensure adequate strength and deformation involved the use of composites shaped as stiff skins on the wavy surface of soft cores (Pimenta \& Robinson, 2014; Quon et al., 2013; Winkelmann et al., 2010). Notable extensions have been achieved by unfolding these shaped skins via premature hardening responses (Pimenta and Robinson 2014) or reloading processes (Quon et al. 2013; Winkelmann et al. 2010). Moreover, the core was generally used to shape the composite profile, and its contributions to the composite behavior has not been fully explored.

To summarize, the current approaches-which involve limitations such as notably increased weight, UV/heat degradation, possible instability on the initiation of loading, unstably reloading responses, and unfavorable hardening responses—are incapable of being an attractive replacement for steel reinforcements. This study aims to overcome these limitations by proposing an innovative concept for a low-density, highyield-strength, large-deformation and stable-loading-behavior composite consisting of FRP helical skins and three-dimensional (3D) print cores. The skin and core materials were carefully selected to achieve lightweight 
and high corrosion-resistance composites. By using the helically braiding technique proposed for this composite, the skins were expected to tightly attach on the core surface with minimum UV/heat impacts. It is expected that the proposed composite would be particularly suitable for use in

(1) internal reinforcements, taking advantage of the high-yield strength, large-deformation and stableloading-behavior potentials of the composites.

(2) near-surface mounted reinforcements because of the lightweight and noncorrosion characteristics of the composites, allowing for easy installation to externally strengthen the concrete elements.

\section{Proposed FRP composites: FRP helical skin and 3D-printed core}

FRP helical skins and 3D-printed cores are developed for the proposed composites to achieve the desired composite stress-strain relations. 3D-printed cores are used to shape the FRP skins. The helical structures ensure a tight skin-core bond by the twisting of skins under tensile loading (Ling 2002). The twisted skins are expected to effectively resist the skin-core delamination and the opening generated due to the core stiffness producing significant stress concentrations at the core edges. Subsequently, various cores with the corresponding stiffness and deformability achieved by 3D printing technology (Dalaq et al. 2016; Wang et al. 2011) can be applied for the composites. Compressing these cores tends to unfold the shaped skins to the amount corresponding to the elastic or plastic core deformations, thereby developing stable nonlinear tensile responses with a considerable stress and strain at skin fracture. As shown in Fig. 1, the initial loads produced slight core deformations that unfolded a limited amount of shaped skins, resulting in stiff composite responses. Subsequently, notable composite extensions could be developed through further compression of the inner cores producing plastic core deformations. To the best of the authors' knowledge, this could be a pioneering study in the use of inner cores to control composite behaviors. The available composites (Pimenta 
\& Robinson, 2014; Quon et al., 2013; Winkelmann et al., 2010) relying exclusively on epoxy bond or stitches are incapable of resisting the opening due to the initial stiffness of the soft cores. Thus, 3D-printed cores with various stiffness have been rarely used to achieve tensile-behavior-designable composites. The use of FRP helical skins and 3D-printed cores can help realize stable nonlinear responses with a considerable strength and extension at skin fracture. It is expected that the proposed composite has potential applications as internal and near-surface mounted reinforcements in concrete structures, owing to its high-strength, largedeformation, low-density, noncorrosion, and tensile-behavior-designable properties.

\section{Concept and mechanical behavior of the composite}

The composite relied on three components (i.e., FRP helical skins, 3D-printed cores and bridges) to develop the nonlinear responses. The FRP helical skins were the main elements that carried the tensile loads (see Fig. 2 (a)). The helical system was expected to effectively resist skin-core delamination by twisting the skins around the core under tensile loading (see Fig. 2 (a)). By using epoxy resin, the profile of the helical skins was shaped by the inner core, as shown in Fig. 2 (b). To prevent FRP skins being cut off by sharp cores, circular-arc cores were applied to define the profiles. The bridges were the linking regions consisting of inner columns with a diameter of $d_{b}$ and helical skins (see Fig. 2 (a) and Fig. 3 (a)). Compressing the core gradually unfolded the shaped skins to develop the corresponding composite extensions to elastic/plastic core deformations through the entire loading process, as shown in Fig. 1. By altering the core configurations, the composite was expected to develop various stress-strain relations under tensile loading. The core configurations included the shell thickness $t_{s}$, brace thickness $t_{b}$, core height $h_{c}$, core span $l_{c}$ and brace angle $\theta_{b}$, as shown in Fig. 3 (a). The cores consisted of outer shells with or without inner braces, as shown in Fig. 3 (b)-(c). Braces were used to improve the strength and/or stiffness of the inner cores, thereby leading 
to stiffer stress-strain responses. Enlarging the brace angles was expected to improve the deformability of the brace-reinforced cores, as shown in Fig. 3 (c)-(d). It should be noted that one-core composites were first constructed to efficiently isolate the impacts of core configurations. Next, the composites with multiple cores were prepared to explore the possibility of extending the composite by using multiple cores. As shown in Fig. 3 (e), these cores were connected by columns having a diameter of $d_{b}$ and a length of $l_{b}$. The FRP composite extension resulted from the unfolded length of the skin and the skin elongation. Compared to the unfolded length, the contribution of the skin elongation to the FRP composite extension was limited. The FRP composite therefore was expected to develop nonlinear stress-strain responses through gradually compression of the inner cores to allow an unfolding corresponding to the elastic/plastic core deformation, as shown in Fig. 1. In the elastic stage, the inner cores were slightly deformed, allowing limitedshaped skins to be unfolded, thereby resulting in stiff composite responses. Notable composite extensions resulted from the plastic core deformations through further compression of the inner cores.

The proposed concept was validated with experimental results, as discussed in the following sections. Based on the experimental results, this study involved the investigation of the impacts of core configurations and composite materials (i.e., FRP amounts and core materials) on the composite behavior.

\section{Materials}

A unidirectional and dry Tyfo® SCH 11-UP strip (Fyfe Co.LLC 2015) was used to make the helical skins.

This material has been widely used for strengthening and repairing concrete structures owing to its low weight and easy-installation properties (Sun et al. 2016). The manufacturer-provided density $\rho_{f}$ and thickness $t_{f}$ were $1.8 \mathrm{~g} / \mathrm{cm}^{3}$ and $0.51 \mathrm{~mm}$, respectively. The selected material was a typical FRP strip with linear-elastic behavior, although it required improvement in terms of its deformability and energy dissipation. Acrylonitrile 
136

137

138

139

140

141

142

143

144

145

146

147

148

149

150

151

152

153

154

155

butadiene styrene (ABS) and polylactic acid (PLA) having considerable stiffness and deformability were used for the inner cores to prevent large core deformations at the initiation of loading and to develop considerable ultimate extensions. For the ABS material, the manufacturer-provided density $\rho_{p}$, modulus $E_{p}$, strength $f_{p}$ and ultimate strain $\varepsilon_{p}$ of the core material were $1 \mathrm{~g} / \mathrm{cm}^{3}, 1.95 \mathrm{GPa}, 41 \mathrm{MPa}$ and 0.21 , respectively. The manufacturer-provided PLA properties were $\rho_{p}=1.2 \mathrm{~g} / \mathrm{cm}^{3}, E_{p}=2.50 \mathrm{GPa}, f_{p}=63 \mathrm{MPa}$ and $\varepsilon_{p}=0.04$.

\section{Fabrication}

The fabrication process of the proposed composites tended to be simple and uniform, resulting in minimum difference among nominally identical composites. Based on this fabrication concept, the composites were fabricated by the following steps, as shown in Fig. 4:

i. The cores and the inner columns were printed using the JG AURORA A8 3D printer and selected core materials (i.e., either ABS or PLA materials). The printer could print structures with a layer thickness of $0.3 \mathrm{~mm}$ and accuracy of $0.1 \mathrm{~mm}$. As shown in Fig. 4 (a), the 3D printing technology provided a feasible, robust and formwork-free method for producing the inner cores having various configurations. The impacts of core configurations (i.e., $h_{c}, l_{c}, \theta_{b}, t_{s}$, and $t_{b}$ ) could be effectively explored, as discussed in the following sections.

ii. The cores and inner columns for all specimens were helically wrapped with three strands of FRP material evenly and carefully separated from a given width of FRP strips having negligible FRP material loss during the fabrication, as shown in Fig. 4 (b). The three-stranded structure was inspired by fishing ropes in which three-stranded polyethylene ropes are helically wound together to resist large axial loading. In this procedure, the FRP material was clipped at one end and the inner system was 

clipped at both ends. The FRP skins were tightly and helically wrapped around the inner cores and columns by rotating the three FRP strands at the other end, as shown in Fig. 4 (c).

iii. The wrapped composite was saturated with epoxy resin, which was the material provided by the manufacturer for the installation of the selected FRP strip (Fyfe Co.LLC 2015). The wrapped composite was held manually and fully saturated in the epoxy for 2 min, as shown in Fig. 4 (d). Next, the ends of the saturated composite were clipped by three sticks for strengthening the tensile ends with additional FRP material (Fig. 4 (e)).

iv. The tensile ends were strengthened using FRP strips. FRP strips with dimensions of $50 \times 50 \mathrm{~mm}$ were prepared for the tensile ends. These FRP strips were saturated with epoxy before wrapping both the ends. The 50-mm-wide strips were selected to ensure a good bond by overwrapping the ends by at least five laps, resulting in more than 6-mm-diameter sections for the tensile ends (see Fig. 4 (e)). Next, the completed composites were cured for 72 hours at $60^{\circ} \mathrm{C}$ before testing, according to the manufacturer's advice (Fyfe Co.LLC 2015).

\section{Experimental program}

To validate the proposed design concept, tensile tests were conducted. Specimens were clipped using the clamps of the displacement-controlled machine for tensile testing (DNS100), in which they were loaded at a rate of $2 \mathrm{~mm} / \mathrm{min}$ as shown in Fig. 5. The specimens were expected to fail in the form of FRP skin fracture when the tensile strength of the FRP skins was reached, or in the form of the inner core crush caused by a considerable core deformation leading to the core failure before skin fracture. A sudden core crush is expected to fracture the skin as a simultaneous result. The nominal tensile stress $f_{\text {com }}$ was therefore calculated as $f_{\text {com }}=P /\left(w_{f} t_{f}\right)$ 
177

where

$$
P=\text { the applied load measured by the load cell of the testing machine, } \mathrm{N} \text {. }
$$

$w_{f}=$ the measured width of the FRP strip used to make the helical skins, mm.

$$
t_{f}=\text { the nominal thickness }(0.51 \mathrm{~mm}) \text { of the FRP strip. }
$$

The nominal strains were obtained from the relative displacements of two points at the composite ends.

The composite ends represented the last points on the axis of the composite, and they were next to the tensile ends, as shown in Fig. 2 (a). The displacements were measured using a high-resolution digital image correlation (DIC) system, as shown in Fig. 5. The nominal stress and strain were used to demonstrate the tensile behavior of the proposed composite. Moreover, the energy dissipation was obtained from integrating the applied loads with respect to the corresponding displacements between two composite ends.

The impacts of FRP amount, core height, core span, shell thickness, core material, core brace and core number were investigated in this study. As the main tensile element, the amount of FRP material determined the ultimate load of the composite and the ultimate deformation of the inner cores. Changes in the core materials or configurations were expected to lead to various core deformations for unfolding the corresponding amounts of shaped skins under tensile loading. Moreover, the composite was also expected to be extendable owing to the use of several cores. To validate those proposed concepts, six groups (A, B, C, D, E and F) of specimens were manufactured as per the details listed in Table 1. Group A consisted of three sets of specimens with identical core configurations wrapped by FRP strands obtained from 10-, 15- and 20-mmwide FRP strips. This group was aimed to demonstrate the impacts of the FRP amount. Group B had another three sets of specimens to reveal the impact of $h_{c} / l_{c}$. All the core parameters except $h_{c} / l_{c}$ were kept constant. Various values of $h_{c} / l_{c}$ were obtained from varying core heights $h_{c}$ (from 2-5 mm) over a constant core span $l_{c}(=16 \mathrm{~mm})$. According to the findings obtained from Group A, a reasonable proportion 
of the FRP amount (in terms of the strip width to the perimeter of the core section at the middle span) was applied to evenly distribute the FRP material on the core surface. Two more sets of tests were performed for Group C to investigate the impacts of shell thickness $t_{s}$ (from $0.5-2 \mathrm{~mm}$ ). All parameters except $t_{s}$ were kept constant. Group D was aimed to explore the impacts of the core materials. In this group, the PLA material was used to print the same core configurations wrapped with an amount of FRP material identical to that of the corresponding ABS composite. As shown in Fig. 3 (c)-(d), inner braces were applied to strengthen the inner cores in Group E. These braces were solid elements having a given thickness $t_{b}$, and they provided the inner cores with support at the middle section. Moreover, the brace could be angled with respect to the vertical axis. Changing the brace angle $\theta_{b}$ was expected to develop various compressive responses. To investigate the angle impacts, the total thickness of the brace was kept constant $(2 \mathrm{~mm})$. The cores were either supported by one 2-mm-thick brace with an angle $\theta_{b}$ of $0^{\circ}$ or two 1-mm-thick braces with angles $\theta_{b}$ of $60^{\circ}$. Group F was used to demonstrate the performance of the composite consisting of several cores, which can be a good reference for extending the proposed composite to a desired length. Another five FRP coupons were also tested; these specimens were $240 \mathrm{~mm}$ long and $15 \mathrm{~mm}$ wide FRP strips with $40 \mathrm{~mm}$ rectangular FRP endtabs. The labeling system applied to identify the specimens involved the group number-set number-unique test number.

\section{Results}

The section describes the experimental results obtained from sixty-five tests to validate the proposed concept and identify the key parameters. 
Five FRP coupons were first tested to obtain the ultimate stresses and strains of the FRP material. Based

on the average values, the strength $f_{f u}$ and ultimate strain $\varepsilon_{f u}$ of the FRP material were $1043 \mathrm{MPa}$ and

0.011 , respectively. The tensile modulus $E_{f}$ obtained from the strength and ultimate strain was $94.55 \mathrm{GPa}$.

Table 1). The shell thickness of Specimen A-ii-5 and C-ii-3 were $1 \mathrm{~mm}$ and $0.5 \mathrm{~mm}$, respectively. Fig. 6 achieve an elastic modulus and ultimate strength comparable to those of the typical coupon tests. 
$240 \mathrm{MPa}$, suggesting that linear-elastic core responses occurred, resulting in slight core deformations. The tensile moduli obtained at 180 MPa were 61.18 GPa and 51.36 GPa for Specimens A-ii-5 and C-ii-3, respectively; terms of energy dissipation. The energy refers to the energy dissipation and the weight stands for the composite weight without the contribution of tensile ends. Based on the experimental results, the proposed in terms of energy dissipation. 

the cores in this section was $3 \mathrm{~mm}$, the mid-section of the cores had perimeters of $19 \mathrm{~mm}$ to be covered with FRP skins. The FRP skins consisted of three strands evenly separated from $10 \mathrm{~mm}-, 15 \mathrm{~mm}-$ and $20 \mathrm{~mm}-$ wide strips (with a constant thickness of $0.51 \mathrm{~mm}$ ), resulting in a strip-width/mid-section-perimeter ratio of $1.1,0.79$ and 0.53 , respectively. It should be noted that all cores were fully and evenly covered by the FRP material. Thus, the composite made by a wider strip was expected to have a larger skin thickness than that of the corresponding composite resulted from a narrower strip.

Figs. 7 (a)-(c) illustrate the stress-strain curves for comparable tests using skins separated via FRP strips having various widths. The comparisons among the typical tests are shown in Fig. 7 (d). When the strip width was increased from $10 \mathrm{~mm}$ to $20 \mathrm{~mm}$, the composites attained more notable nonlinear responses. Moreover, increasing the strip width resulted in limited modulus improvement at the initial stresses up to $200 \mathrm{MPa}$, as shown in Fig. 7 (d). Then, the composite having a wider strip tended to produce more core deformation, resulting in a larger composite deformation. As shown in Table 2, increasing the strip width from $10 \mathrm{~mm}$ to

$27415 \mathrm{~mm}$ improved the average ultimate stress from $693 \mathrm{MPa}$ to $768 \mathrm{MPa}$, the average ultimate strain from 0.019 to 0.039 , and the average energy dissipation from $1.64 \mathrm{~J} / \mathrm{g}$ to $7.00 \mathrm{~J} / \mathrm{g}$. Table 2 also provides the standard deviations of these average values. A continually increasing width from $15 \mathrm{~mm}$ to $20 \mathrm{~mm}$, however, produced less improvements in terms of the ultimate stresses, ultimate strains and energy dissipation. Thus, the FRP amount influenced the composite responses in terms of the stress-strain shape, energy dissipation, and improvable stress-strain curves, a strip-width/mid-section-perimeter ratio of 0.79 was used to explore the impacts of core configuration $\left(h_{c} / l_{c}\right)$. 

investigate the impacts of core height and span. All parameters except $h_{c} / l_{c}$ were kept the same as listed in

Table 1. Various $h_{c} / l_{c}$ ratios resulted from a constant span $(=16 \mathrm{~mm})$ and varying heights (from $2-5 \mathrm{~mm}$ ).

To effectively wrap the inner cores with various heights, a previously recommended strip-width/mid-section-

perimeter ratio of 0.79 was used to calculate the required FRP amount. The required strip widths for cores with a height of $2 \mathrm{~mm}, 3 \mathrm{~mm}, 4 \mathrm{~mm}$, and $5 \mathrm{~mm}$ were, therefore, $10 \mathrm{~mm}, 15 \mathrm{~mm}, 20 \mathrm{~mm}$ and $25 \mathrm{~mm}$, respectively. All composites having cores with a height of $5 \mathrm{~mm}$ failed in core crush. The other composites produced more notable nonlinear stress-strain responses, as shown in Fig. 8 (a), Fig. 7 (b) and Fig. 8 (b). Composites with a height of $5 \mathrm{~mm}$ failed prematurely in core crush, producing the least ultimate stresses, as shown in Fig. 8 (c). This suggested that composites with a larger height had greater potentials for developing nonlinear tensile responses, but they could be much more vulnerable to core crush. The comparisons among the typical tests are shown in Fig. 8 (d). It can also be seen that increasing the height increased the composite deformability and reduced the stiffness at both the elastic and plastic stages. As listed in Table 2, increasing the value of $h_{c} / l_{c}$ from $2 / 16$ to $4 / 16$ resulted in lower average stresses at skin fracture (from $822 \mathrm{MPa}$ to $687 \mathrm{MPa}$ ), larger average ultimate strains (from 0.012 to 0.09 ) and larger average energy dissipation (from but developed considerable average ultimate strains (0.054) and average energy dissipation ( $3.15 \mathrm{~J} / \mathrm{g})$. Given tensile behavior, and this value was used to explore the impacts of shell thickness. 
305

Composites with shell thicknesses of $2 \mathrm{~mm}, 1 \mathrm{~mm}$ and $0.5 \mathrm{~mm}$ were tested to investigate the impacts of shell thickness $t_{s}$. The experimental results of fifteen tests from three sets (i.e., C-i, A-ii, and C-ii) were compared, as given in Table 2. All the parameters except shell thickness were kept constant. All the specimens having a shell thickness of $0.5 \mathrm{~mm}$ failed in core crush. The other tests failed at their ultimate stresses because of skin fracture. As shown in Figs. 9 (a)-(b), reducing the shell thickness tended to produce softer nonlinear stress-strain curves and less nonlinear responses. The comparisons among the typical tests are shown in Fig. 9 (c); the results suggest that the shell thickness has limited impact on the initial modulus. Instead, the core with a thinner thickness tended to develop more notable nonlinear stress-strain responses at a lower stress level. Composites having a shell thickness of $2 \mathrm{~mm}$ developed the least deformations (average ultimate strain $=0.017$ ) and energy dissipation (average energy/weight $=1.65 \mathrm{~J} / \mathrm{g}$ ), as listed in Table 2 . The slightly deformed cores fractured skins at relatively lower ultimate stresses (average $=643 \mathrm{MPa}$ ). Reducing the thickness from $2 \mathrm{~mm}$ to $1 \mathrm{~mm}$ increased the ultimate stresses and strains (i.e., for Specimens C-i and A-ii listed in Table 2). Continually reducing the thickness from $1 \mathrm{~mm}$ to $0.5 \mathrm{~mm}$ resulted in much larger deformations and energy dissipation but inner core crush occurred at a relatively lower ultimate stress (average $=625 \mathrm{MPa}$ ). These observations indicated the trends of less notable nonlinear responses and larger deformations with increasing shell thickness.

\section{Impacts of core material}

Ten composites (from two sets i.e., B-ii and D-i) with a $h_{c} / l_{c}$ of $4 / 16$, core thickness of $1 \mathrm{~mm}$, strip width of $20 \mathrm{~mm}$ and different core materials (ABS or PLA) were compared, as given in Table 2. The use of PLA material aimed to produce nonlinear stress-strain responses at higher "yield" stresses. When applying the 
proposed composite to strengthen RC, a higher "yield" stress would be more effective in controlling the concrete cracks.

In the evaluation described in this section, all specimens failed in skin fracture. As shown in Fig. 10 (a), most composites using the PLA material remained elastic at higher stresses (approximately $300 \mathrm{MPa}$ ). When the ABS material was used, all the composites produced plastic responses before $300 \mathrm{MPa}$ (see Fig. 8 (b) and Fig. 10 (b)). The composites using PLA material eventually failed at approximately $487 \mathrm{MPa}$ with an average strain of 0.046, while the comparable composites with ABS material developed ultimate stresses more than $670 \mathrm{MPa}$ and ultimate strains no less than 0.084. Nevertheless, the PLA composites produced much more convergent loading responses than those of the ABS composites, demonstrating their merits of printing quality. The comparisons among the typical tests using ABS and PLA materials to print cores are shown in Fig. 10 (b). It can be seen that the material properties have limited impact on the initial modulus. Instead, a stiffer material (with a higher $E_{p}$, and $f_{p}$ ) tended to develop nonlinear strain-stress responses at a higher stress than the comparable composite that used a softer material to print the inner cores did.

\section{Impacts of core brace}

Fifteen tests (from three sets i.e., E-i, E-ii, and A-ii) were compared to investigate the impacts of core brace.

All the parameters except brace arrangements were kept constant. The brace arrangements included one 2 mm-thick, $0^{\circ}$ brace and two 1 mm-thick $60^{\circ}$ braces. This selection was made to provide braces with an equivalent overall thickness, i.e., one 2-mm-thick brace or two 1-mm-thick braces. Moreover, the bracereinforced tests were also compared with corresponding brace-free tests (Specimen A-ii) to isolate the brace impacts. 
All the tests failed in skin fracture. With the braces, the composites developed stiffer stress-strain responses than those of the comparable tests in which the braces were not used (see Fig. 11 and Fig. 7 (b)). The composites using braces achieved a stress of $400 \mathrm{MPa}$ at a strain less than 0.01, as shown in Fig. 11 (a)-(b). The only exception (E-ii-5) developed a stress of $400 \mathrm{MPa}$ at a strain of approximately 0.012 . For the composites not using braces, the stresses at the strain of 0.01 were much less than $400 \mathrm{MPa}$, as shown in Fig. 7 (b). Similarly, the stresses of brace-reinforced composites at the strain of 0.02 were approximately 600 MPa, which was no less than the stresses obtained from their comparable tests that did not use braces. The comparisons among the typical tests using various braces and no braces are shown in Fig. 11 (c). The findings also suggest that the use of the brace and reducing the brace angle allowed the development of stiffer nonlinear responses and reduction of the deformability.

Increasing the brace angle from $0^{\circ}$ to $60^{\circ}$ resulted in limited increases in the average ultimate stresses (from $670 \mathrm{MPa}$ to $692 \mathrm{MPa}$ ) but considerable improvements in terms of the average ultimate strains (from 0.024 to 0.030 ) and average energy dissipation (from $3.3 \mathrm{~J} / \mathrm{g}$ to $4.2 \mathrm{~J} / \mathrm{g}$ ). Compared to those in the tests with braces, the composites that did not use braces achieved much greater average ultimate stress (768 MPa), average ultimate strain (0.039) and average energy dissipation $(7.00 \mathrm{~J} / \mathrm{g})$.

As discussed above, the brace-reinforced cores tended to produce stiffer stress-strain relations with lower ultimate stresses and strains as well as less energy dissipation. Increasing the brace angle from $0^{\circ}$ to $60^{\circ}$ improved the ultimate strain and energy dissipation.

\section{Performance of composites with multiple cores}

Ten tests (from two sets, i.e., F-i and F-ii) were performed to investigate the impacts of core number. The cores were connected by $10-\mathrm{mm}$-long inner columns. Next, the inner cores and columns were helically 

for the brace-reinforced and brace-free composites, respectively (see Table 1).

As shown in Fig. 12 (a), the brace-reinforced composites developed nonlinear stress-strain responses, which were reasonably similar to those of the comparable tests with one single core (see. Fig. 11 (a)) in terms of the curve shapes and ultimate stresses. The ultimate strains corresponding to three-core composites were a little less than those of the comparable composites with one core (i.e., Specimen E-i listed in Table 2). The reason could be that the stiff bridges compromised the entire deformability of the composite with multiple cores, resulting in less ultimate strains. For the brace-free composites, tests having multiple cores produced much less ultimate strains (see Fig. 12 (b)) compared to those of the specimens with one core (i.e., Specimen A-ii shown in Fig. 7 (b)), thereby indicating that the stiff bridges had a more considerable impact on the composites with brace-free cores. Moreover, all tests having three cores failed in skin fracture. This suggested that the proposed helical system effectively resisted the skin-core delamination and the opening stresses at the core-bridge connections. Otherwise, the composites would have failed in premature delamination owing to the development of much lower ultimate stresses. Thus, the composite can be extended by using multiple cores. Fig. 12 (c) illustrates the typical tests of composites having multiple-braced or brace-free cores. Similarly, the brace had limited impact on the initial modulus but tended to reduce the composite deformability. This trend is the same as that observed from the corresponding tests using a single core. This suggests that the parametric studies of composites having one-single core can be used for predicting the trend of the corresponding composites with multiple cores. 
This study proposed a novel concept to achieve high-strength, large-deformation, ductile, tensile-behaviordesignable FRP composites. The composite consists of three components: (i) inner cores (providing designable stiffness, deformation and profile to shape skins), (ii) helical skins (providing primary resistance for tensile loads and openings at core edges), and (iii) bridges (providing connections to achieve a desired length). The experimental results from sixty-five tests validated the capability of (1) the helical system to resist the opening stress and (2) the proposed composite to develop nonlinear stress-strain responses. Moreover, the impacts of FRP amount, core configurations (i.e., height $h_{c}$, span $l_{c}$, shell thickness $t_{s}$, inner braces) and core material within the investigated ranges are clarified as follows. pronounced nonlinear responses and larger ultimate strains. Moreover, increasing the core height tended $\mathrm{mm}, t_{s}=1 \mathrm{~mm}$, and $h_{c} / l_{c}=4 / 16$.

2. The shell thickness is another important parameter that can influence the composite behavior. Although composite. A stiffer material (e.g., PLA with a higher $E_{p}$, and $f_{p}$ ) tended to develop nonlinear strain- 
407 stress responses at a higher stress than the comparable composite that employed a softer material (e.g.,

408 ABS) to print inner cores did. Moreover, a stiffer PLA material allowed less core deformation, resulting

409 in less notable nonlinear responses and fracturing skins at lower stresses than those of comparable tests

$410 \quad$ using a softer ABS material to print cores.

411 4. Core braces can also be used to composite behaviors. Composites supported by core braces tended to produce stiffer stress-strain relations with lower ultimate stresses and strains than the comparable one that did not use braces did. Increasing the brace angle from $0^{\circ}$ to $60^{\circ}$ improved the ultimate strain.

4145 . The proposed composite could be extended by using multiple cores.

\section{Acknowledgments}

417 Laboratory of Ministry of Education for Mechanics on Western Disaster and Environment, the School of

418 Civil Engineering and Mechanics at Lanzhou University, and the School of Engineering and the Environment 419 at the University of Southampton are gratefully acknowledged. The authors express their thanks to Dr. Wang, 


\section{References}

423

Achintha, M., Alami, F., Harry, S., and Bloodworth, A. (2018). "Towards Innovative FRP Fabric Reinforcement in Concrete Beams: Concrete-CFRP Bond.” Magazine of Concrete Research, 70(15), $785-797$.

Achintha M. (2009). "Fracture analysis of debonding mechanism for FRP plates." University of Cambridge.

Allaer, K., De Baere, I., Lava, P., Van Paepegem, W., and Degrieck, J. (2014). “On the in-plane mechanical properties of stainless steel fibre reinforced ductile composites." Composites Science and Technology, Elsevier Ltd, 100, 34-43.

Behnam, B., and Eamon, C. (2013). "Reliability-based design optimization of concrete flexural members reinforced with ductile FRP bars.” Construction and Building Materials, Elsevier Ltd, 47, 942-950.

Cabrera, J. G. (1996). "Deterioration of concrete due to reinforcement steel corrosion.” Cement and Concrete Composites, 18(1), 47-59.

Czél, G., Jalalvand, M., Wisnom, M. R., and Czigány, T. (2017). “Design and characterisation of high performance, pseudo-ductile all-carbon/epoxy unidirectional hybrid composites." Composites Part B: Engineering, 111, 348-356.

Czél, G., and Wisnom, M. R. (2013). "Demonstration of pseudo-ductility in high performance glass/epoxy composites by hybridisation with thin-ply carbon prepreg." Composites Part A: Applied Science and Manufacturing, 52, 23-30.

Dalaq, A. S., Abueidda, D. W., and Abu Al-Rub, R. K. (2016). "Mechanical properties of 3D printed interpenetrating phase composites with novel architectured 3D solid-sheet reinforcements." Composites Part A: Applied Science and Manufacturing, Elsevier Ltd, 84, 266-280.

Faustino, P., Brás, A., and Ripper, T. (2015). "The effect of corrosion inhibitors on the modelling of design 
Fyfe Co.LLC. (2015). “Tyfo ® SCH-11UP Composite.”

Grace, N. F., Ragheb, W. F., and Abdel-Sayed, G. (2004). "Development and application of innovative triaxially braided ductile FRP fabric for strengthening concrete beams." Composite Structures, 64(34), 521-530.

Jalalvand, M., Czél, G., and Wisnom, M. R. (2015). "Damage analysis of pseudo-ductile thin-ply UD hybrid composites - A new analytical method.” Composites Part A: Applied Science and Manufacturing, Elsevier Ltd, 69, 83-93.

Ling, F. F. (2002). Fundamentals of Surface Mechanics: With Applications (Mechanical Engineering Series). Springer.

Lou, T., and Karavasilis, T. L. (2018). "Time-dependent assessment and deflection prediction of prestressed concrete beams with unbonded CFRP tendons." Composite Structures, Elsevier, 194(April), 365-376.

Lou, T., Liu, M., Lopes, S. M. R., and Lopes, A. V. (2017a). "Effect of bond on flexure of concrete beams prestressed with FRP tendons.” Composite Structures, Elsevier Ltd, 173, 168-176.

Lou, T., Lopes, S. M. R., and Lopes, A. V. (2016). "Response of continuous concrete beams internally prestressed with unbonded FRP and steel tendons.” Composite Structures, Elsevier Ltd, 154, 92-105.

Lou, T., Lopes, S. M. R., and Lopes, A. V. (2017b). "Effect of linear transformation on nonlinear behavior of continuous prestressed beams with external FRP cables.” Engineering Structures, Elsevier Ltd,

Mohan, P. (2013). “A Critical Review: The Modification, Properties, and Applications of Epoxy Resins.” Polymer - Plastics Technology and Engineering, 52(2), 107-125. 
Quon, C., Cheng, L., Li, Y., and Yu, W. (2013). “Confinement of concrete with hybrid FRP bistable structures." Cement and Concrete Composites, 37(1), 222-231.

Sun, W. (2018). "Development of a testing methodology for the design and quality control of carbon fiber reinforced polymer (CFRP) anchors.” Construction and Building Materials, Elsevier Ltd, 164, 150163.

Sun, W., and Ghannoum, W. M. (2015). "Modeling of anchored CFRP strips bonded to concrete.” Construction and Building Materials, Elsevier Ltd, 85, 144-156.

Sun, W., Jirsa, J. O., and Ghannoum, W. M. (2016). "Behavior of anchored carbon fiber-reinforced polymer strips used for strengthening concrete structures.” ACI Materials Journal, 113(2), 163-172.

Sun, W., Liu, H., Wang, Y., and He, T. (2018). "Impacts of configurations on the strength of FRP anchors." Composite Structures, 194(February), 126-135.

Sun, W., Peng, X., Liu, H., and Qi, H. (2017a). "Numerical studies on the entire debonding propagation process of FRP strips externally bonded to the concrete substrate." Construction and Building Materials, Elsevier Ltd, 149, 218-235.

Sun, W., Peng, X., and Yu, Y. (2017b). "Development of a simplified bond model used for simulating FRP strips bonded to concrete." Composite Structures, 171, 462-472.

US Federal Highway Administration. (2001). "Long-term effectiveness of cathodic protection systems on highway structures.” Publication No. FHWA-RD-01-096, FHWA.

Wang, L., Lau, J., Thomas, E. L., and Boyce, M. C. (2011). “Co-continuous composite materials for stiffness, strength, and energy dissipation.” Advanced Materials, 23(13), 1524-1529.

Winkelmann, C., Kim, S. S., and La Saponara, V. (2010). “Design and development of hybrid composite 

Elsevier Ltd, 93(1), 171-178. corrugated composites for candidate materials of flexible wing structures." Composites Part A: Applied Science and Manufacturing, 37(10), 1578-1586. aluminium particles / epoxy composite.” Progress in Organic Coatings, Elsevier B.V., 101, 305-308.

495 


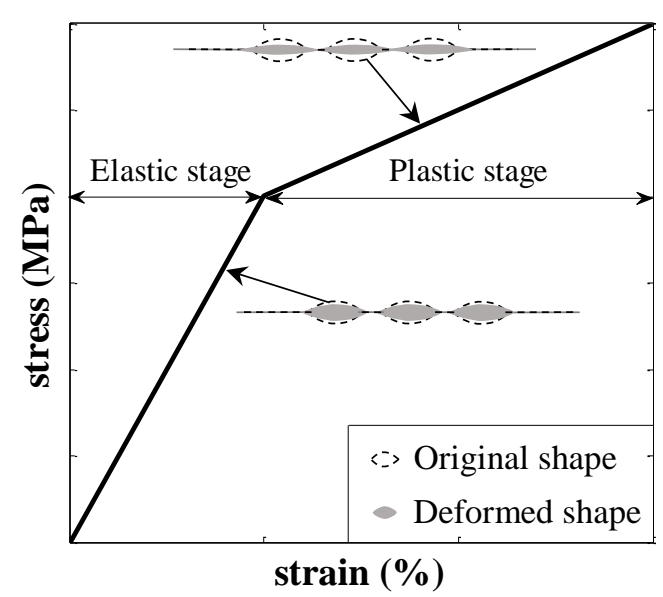

510

Fig. 1. Typical tensile responses of the proposed composite 


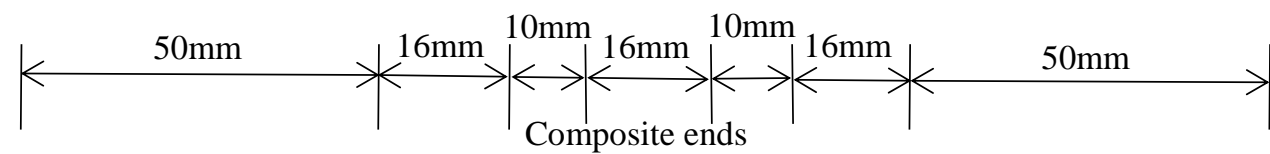

526

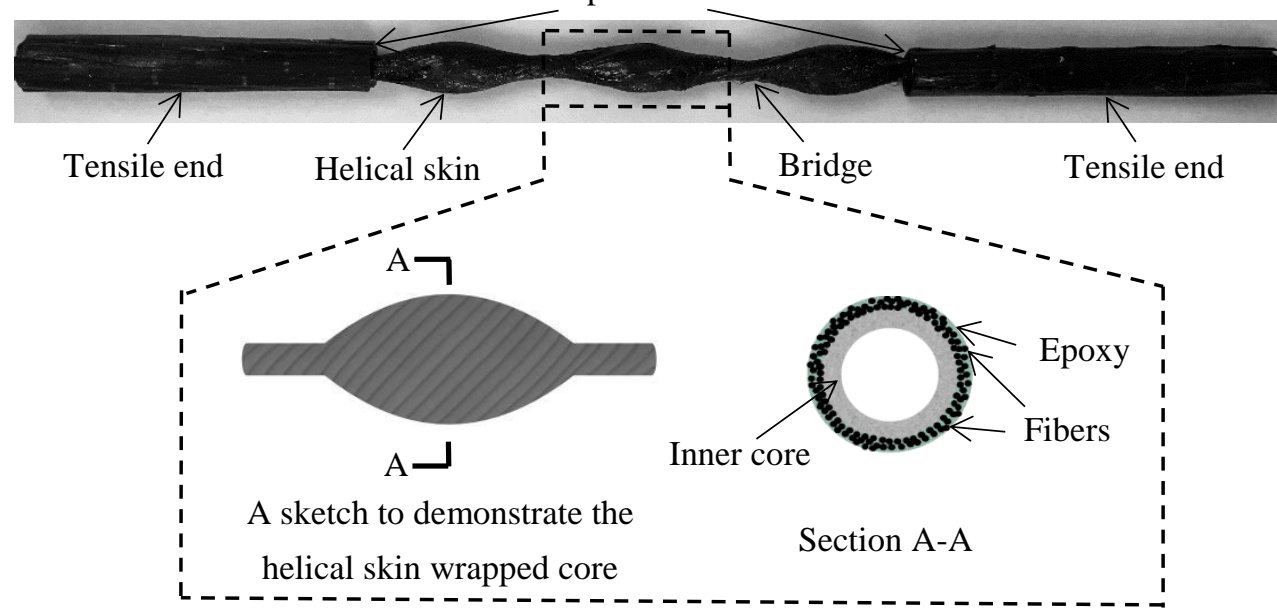

(a) A typical composite

(b) Inner system consisting of cores and columns 


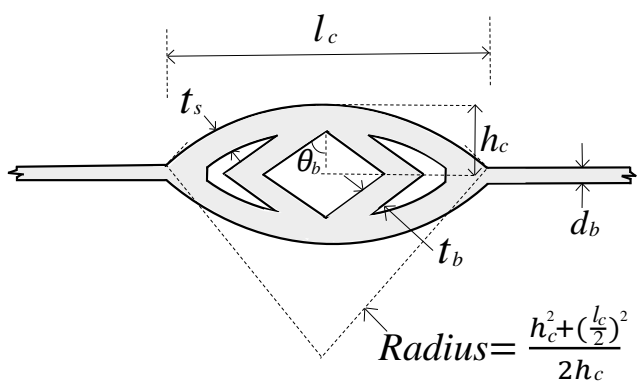

(a) Geometry of an inner core with two braces

534

535

536

537

538

539

540

541

542

543

544

Outer shell

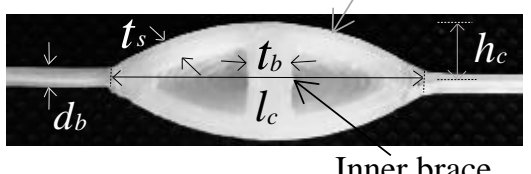

(c) A typical core with a $0^{\circ}$ brace

Outer shell

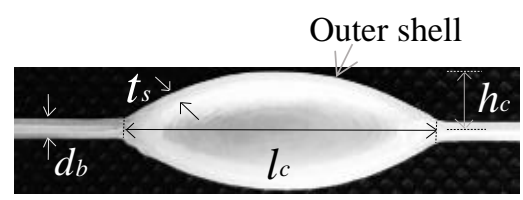

(b) A typical core without braces

(d) A typical core with two $60^{\circ}$ braces

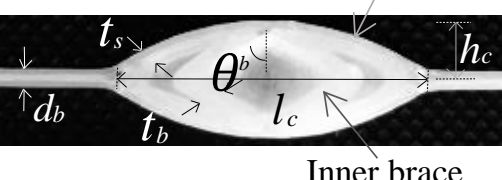

Outer shell

Inner brace

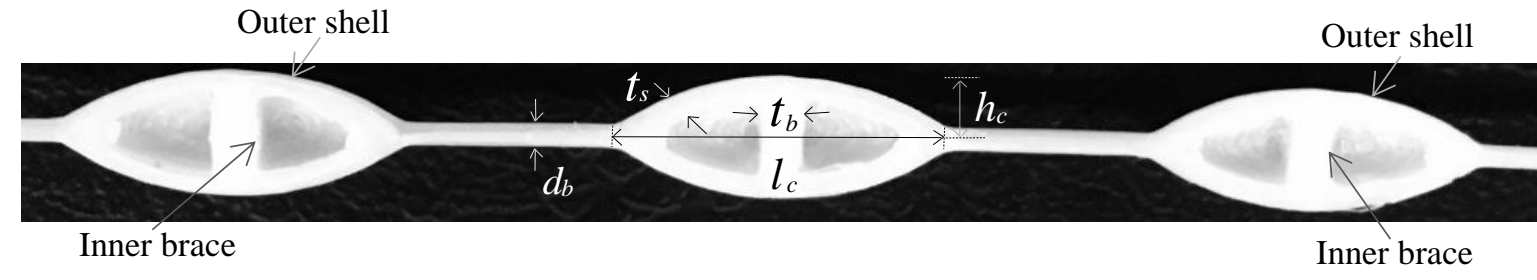

(e) A typical composite having three cores

Fig. 3. Core configurations 


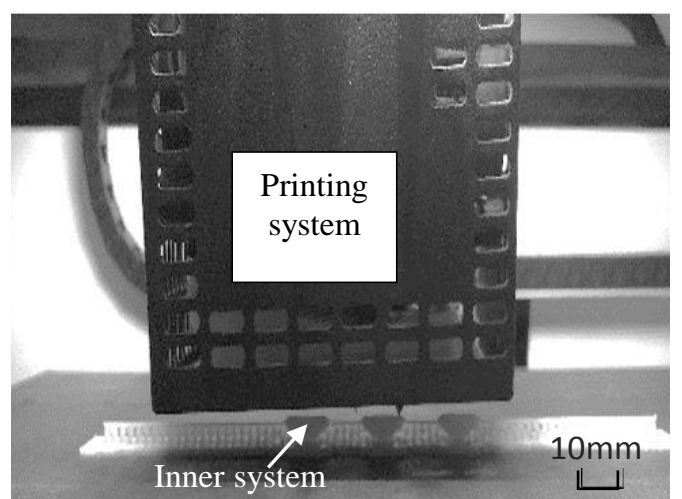

(a) Printing inner cores and inner columns

547

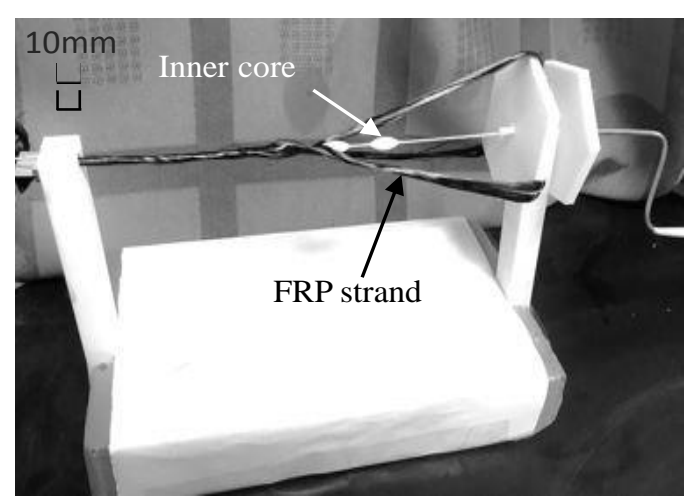

(c) Helically wrapping the printed system

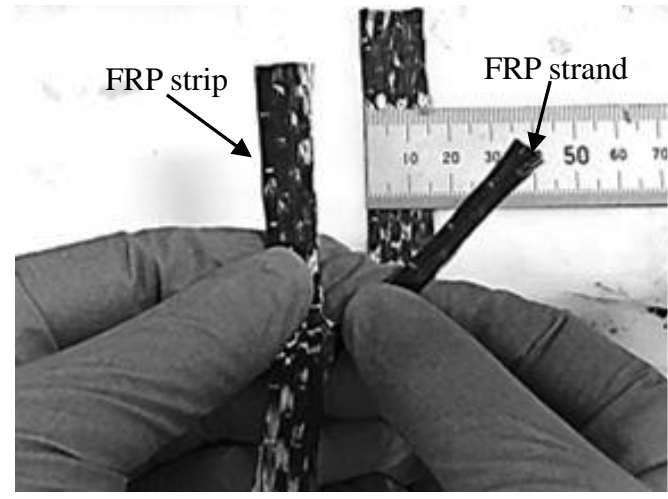

(b) Separating strands from a given width of an FRP strip

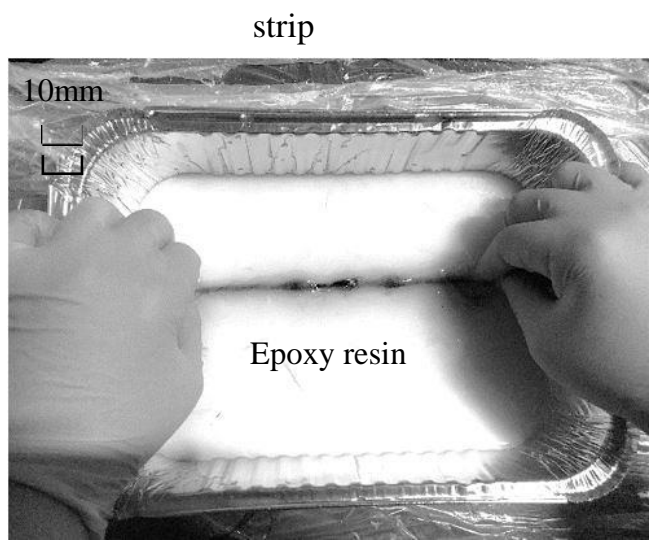

(d) Saturating the wrapped composite

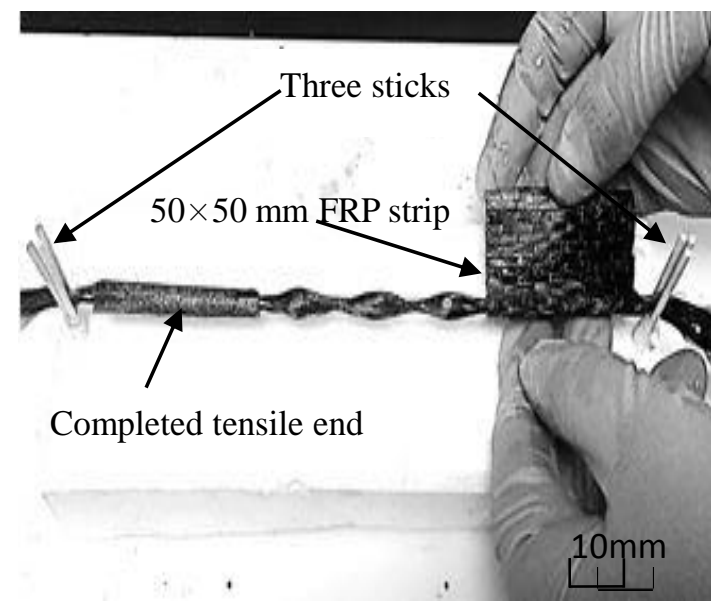

(e) Wrapping both ends for tensile testing

Fig. 4. Fabrication of the proposed composite 
555

556

557

558

559

560

561

562

563

564

565

566

567

568

569

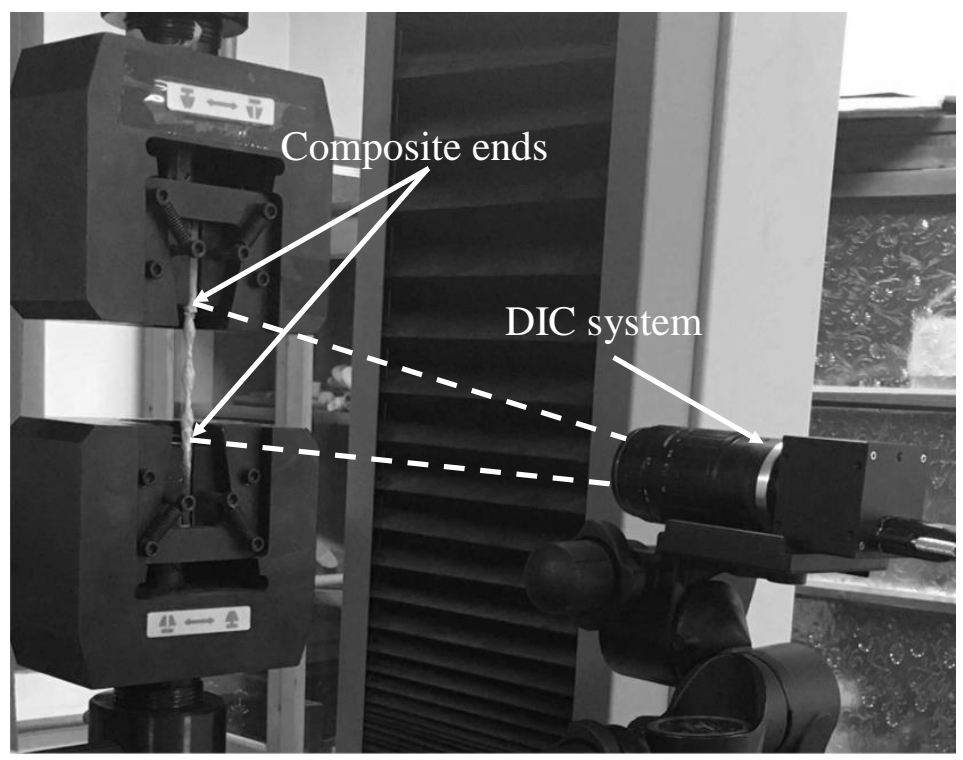

570

Fig. 5. Test setup

571 

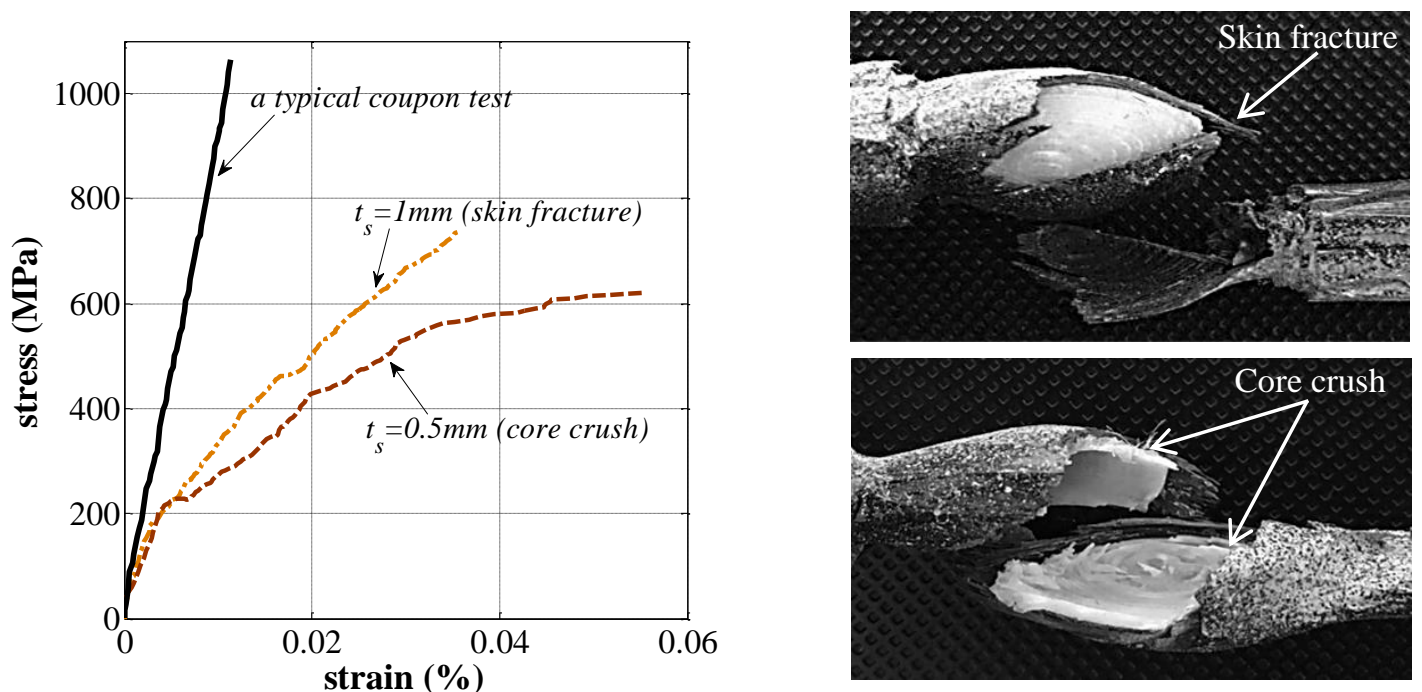

573 Fig. 6. Stress-strain plots for typical composites using 15 -mm-wide FRP strips, ABS material, $h_{c} / l_{c}$ of 3/16,

574 various shell thicknesses and failure types of skin fracture (A-ii-5) or core crushing (C-ii-3)

575

576

577

578 
579

580

581

582

583

584

585

586

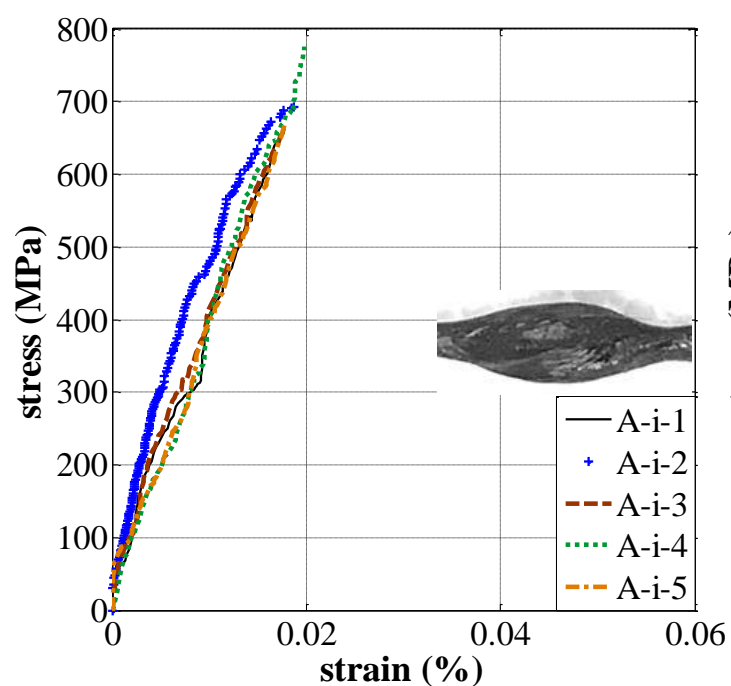

(a) 10-mm-wide FRP strips

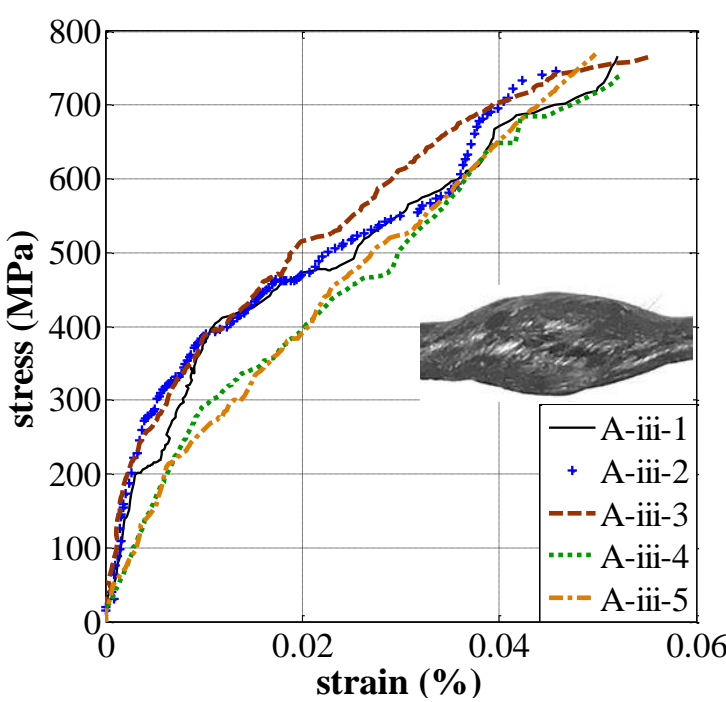

(c) 20-mm-wide FRP strips

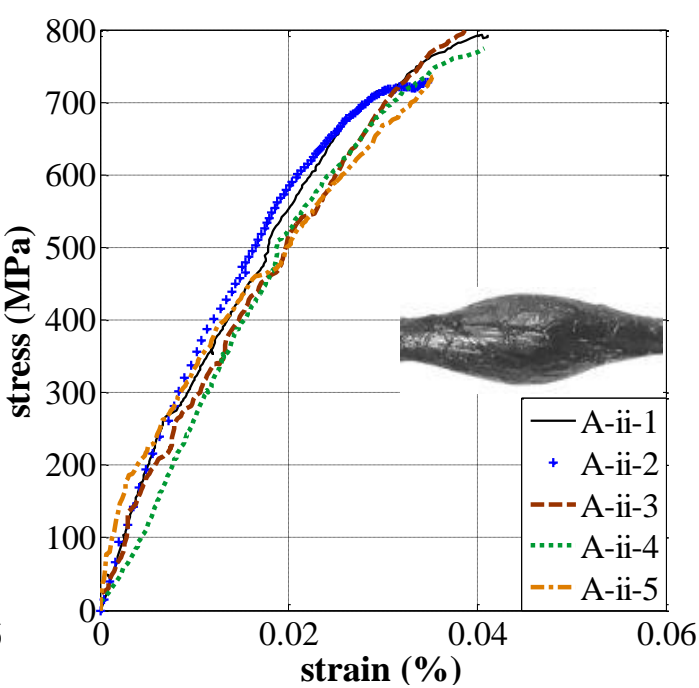

(b) 15-mm-wide FRP strips

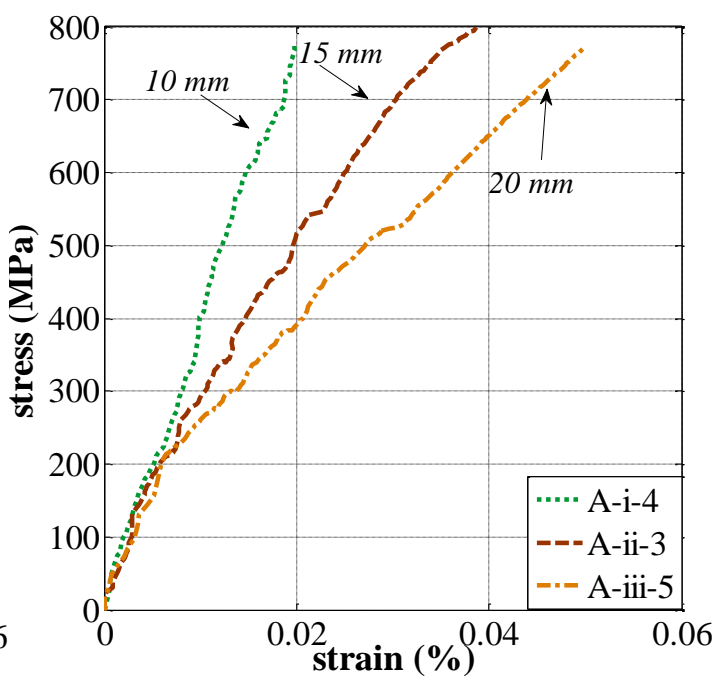

(d) Typical tests with various strip widths

Fig. 7. Stress-strain curves for composites involving the use of various strip widths to construct the FRP skins 


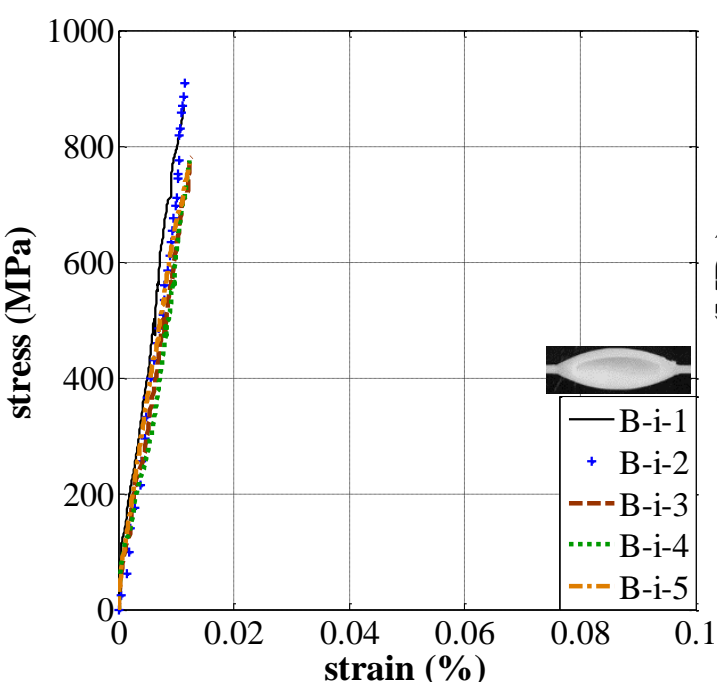

(a) 2-mm-high cores

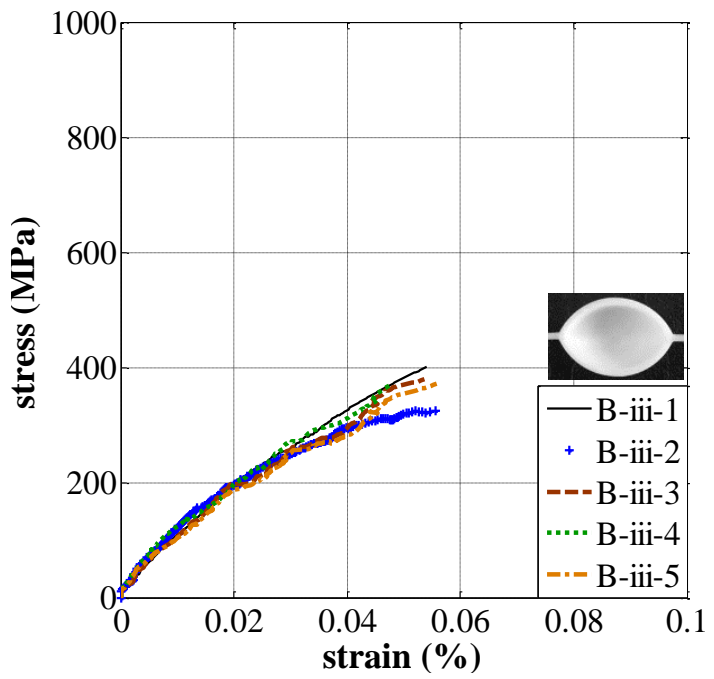

(c) 5-mm-high cores

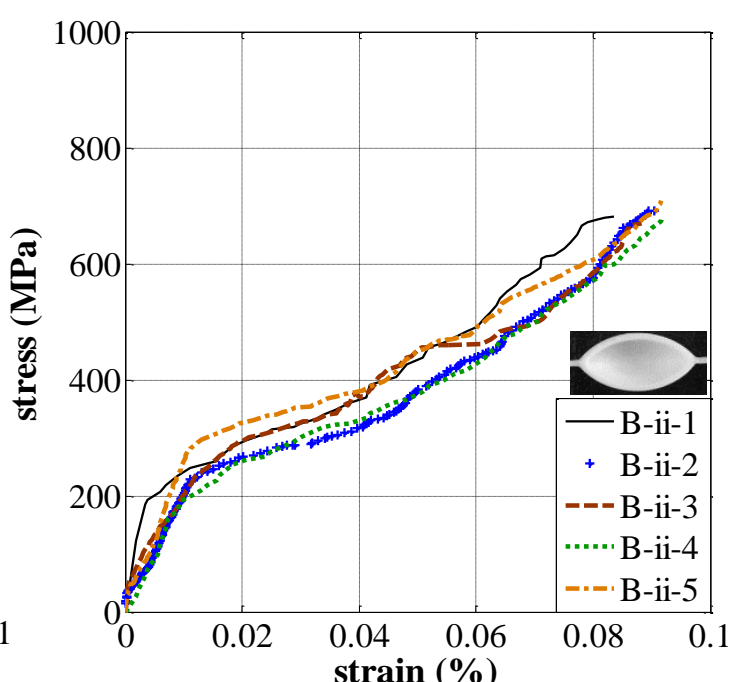

(b) 4-mm-high cores

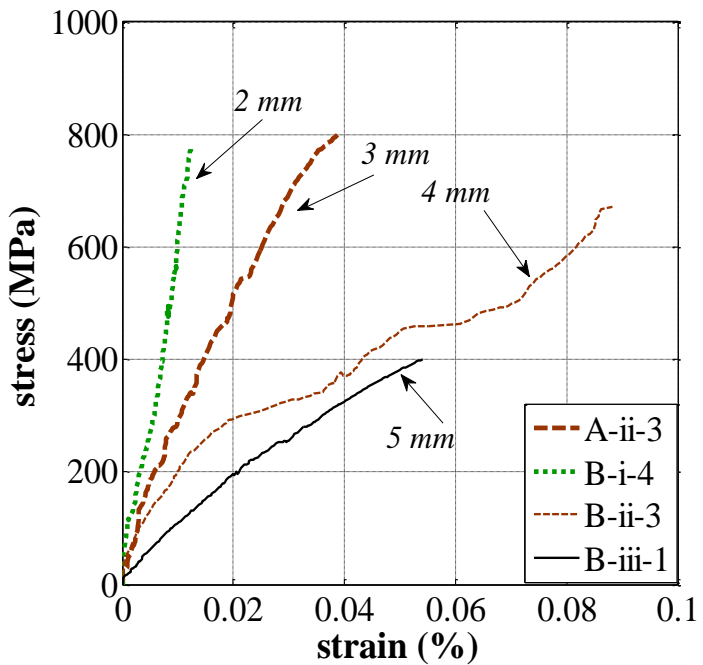

(d) Typical tests with various core heights

Fig. 8. Stress-strain curves for composites having various core heights 


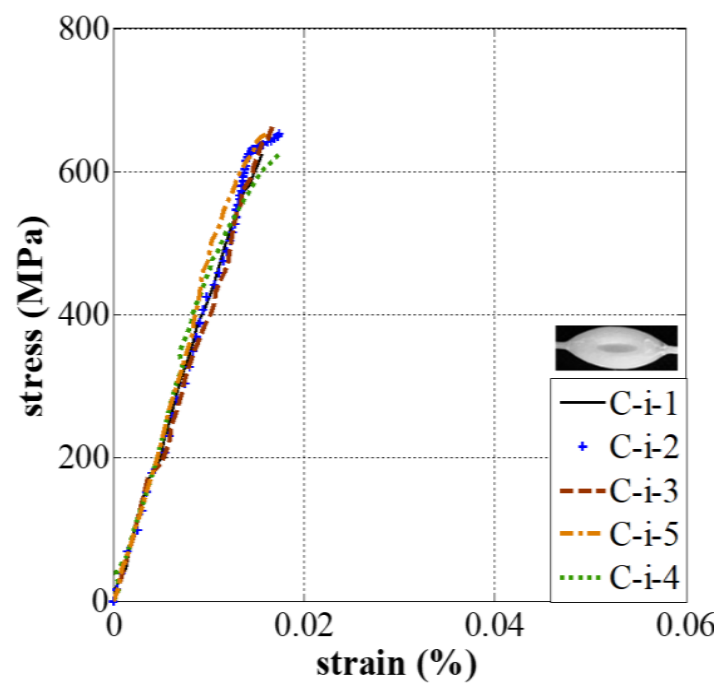

(a) Shell thickness $t_{s}=2 \mathrm{~mm}$

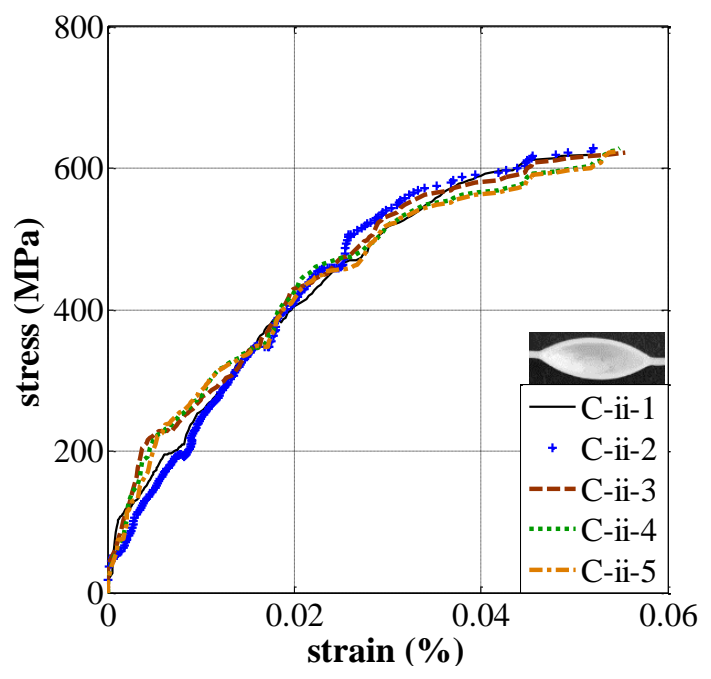

(b) Shell thickness $t_{s}=0.5 \mathrm{~mm}$
597

598

599

600

601

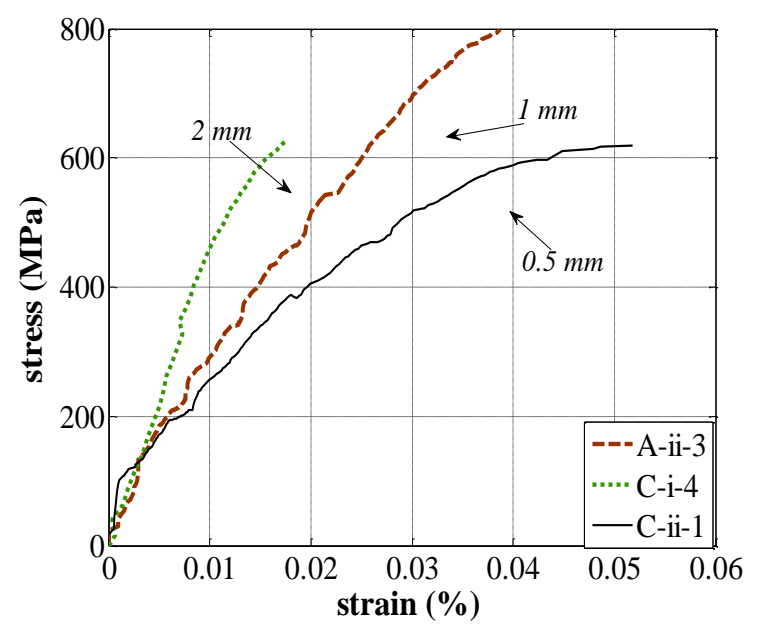

(c) Typical tests with various shell thicknesses

Fig. 9. Stress-strain curves for composites having various shell thicknesses 


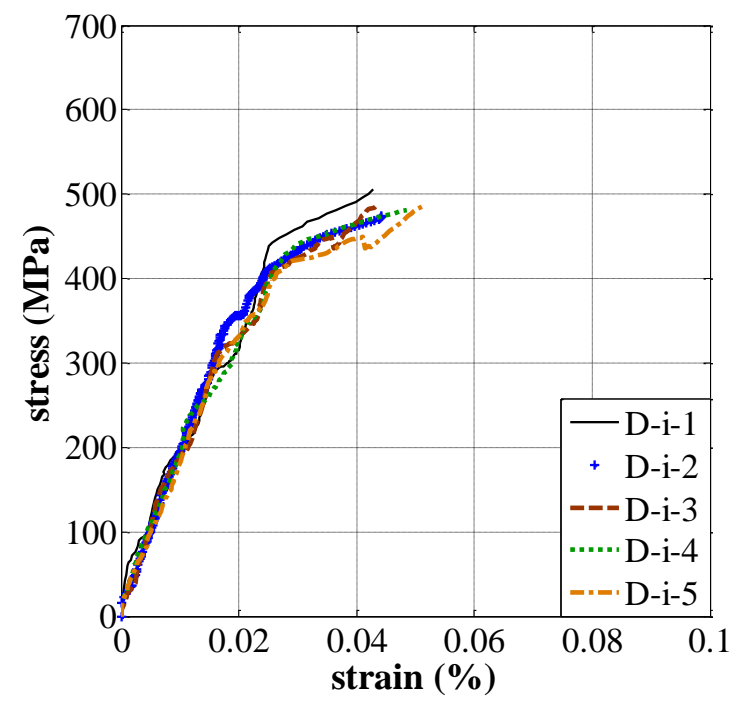

(a) Composites with a PLA core

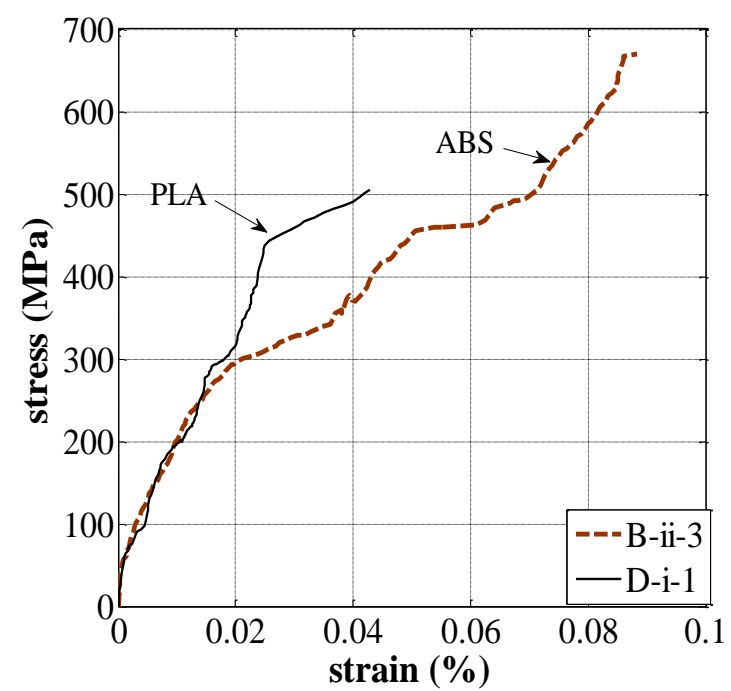

(b) Typical tests with various core materials

Fig. 10. Stress-strain curves for composites involving the use of PLA or ABS material to print cores 
607

608

609

616

617

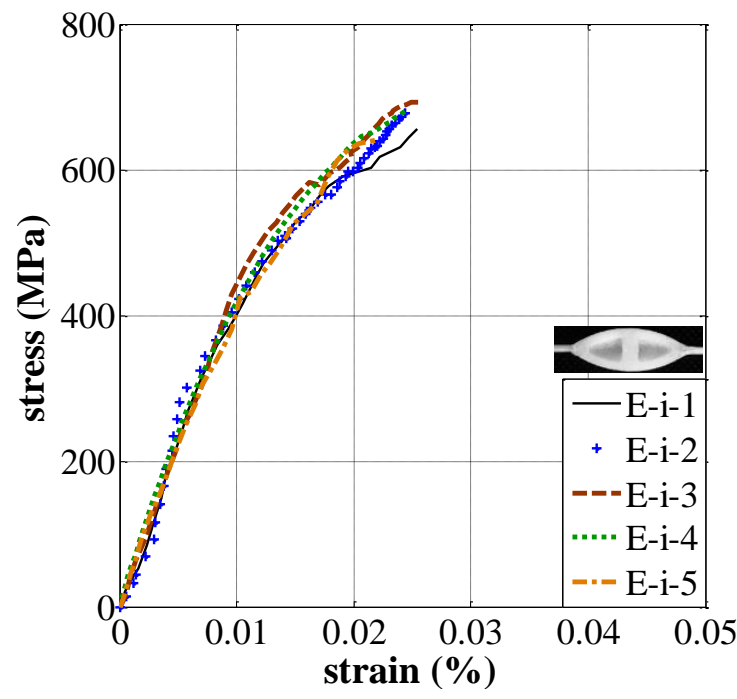

(a) Brace angle $\theta_{b}=0^{\circ}$

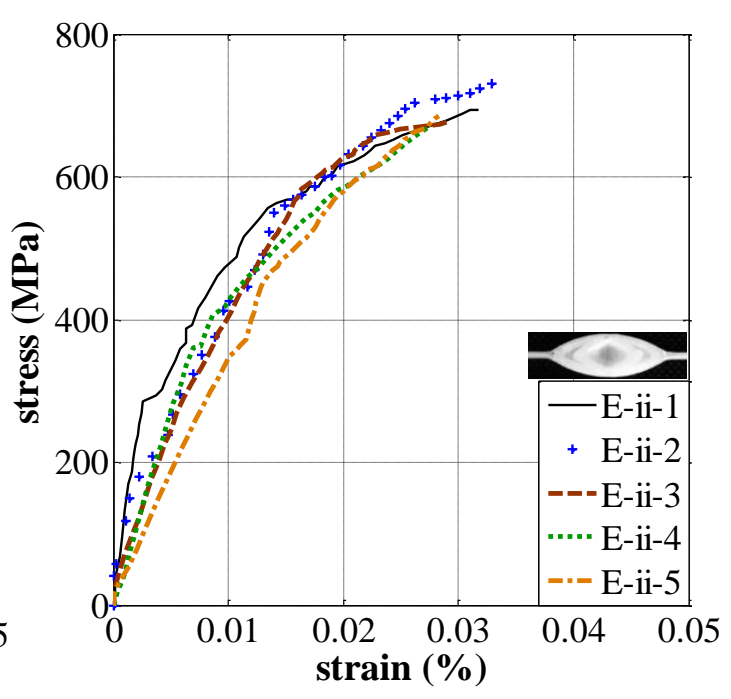

(b) Brace angle $\theta_{b}=60^{\circ}$

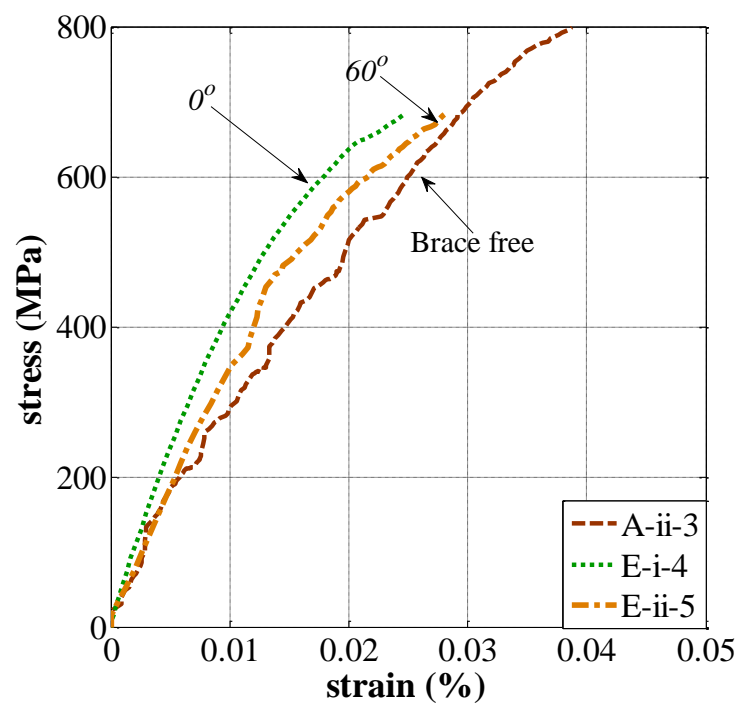

(c) Typical tests with various brace arrangements

Fig. 11. Stress-strain curves for composites having various brace arrangements 


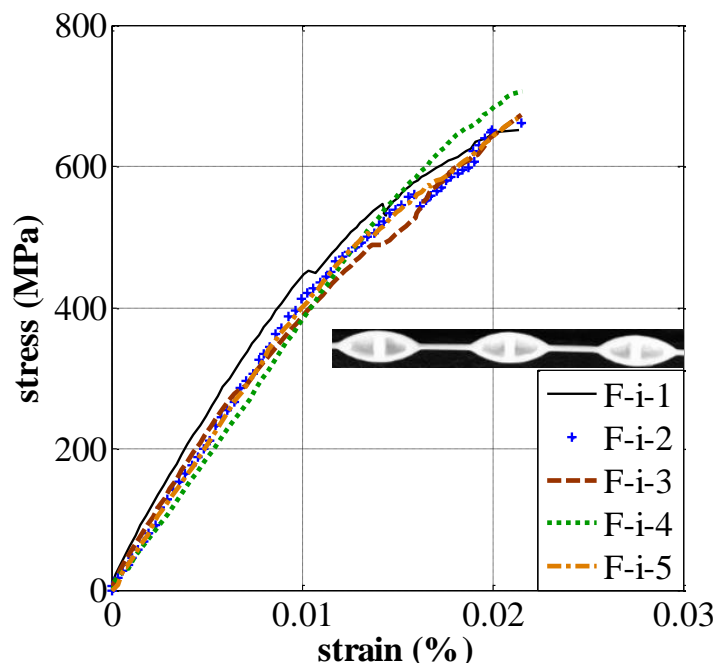

(a) Brace reinforced cores

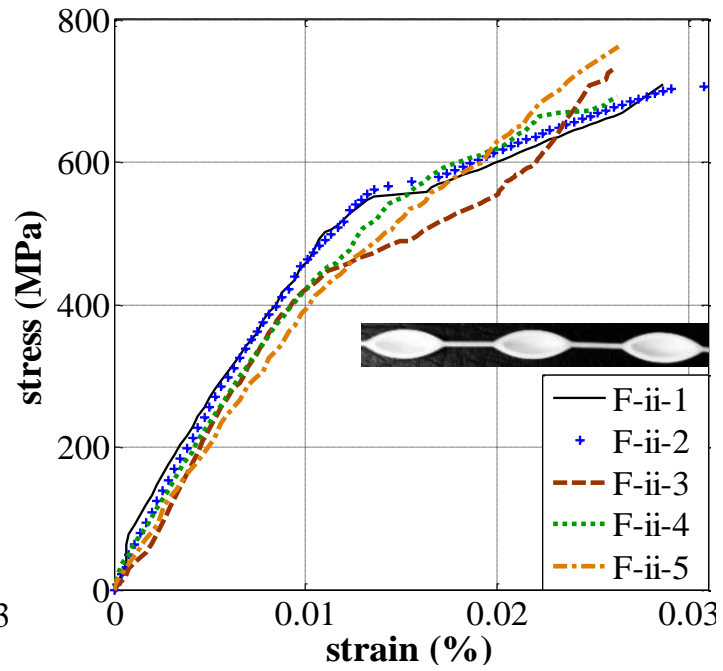

(b) Brace free cores

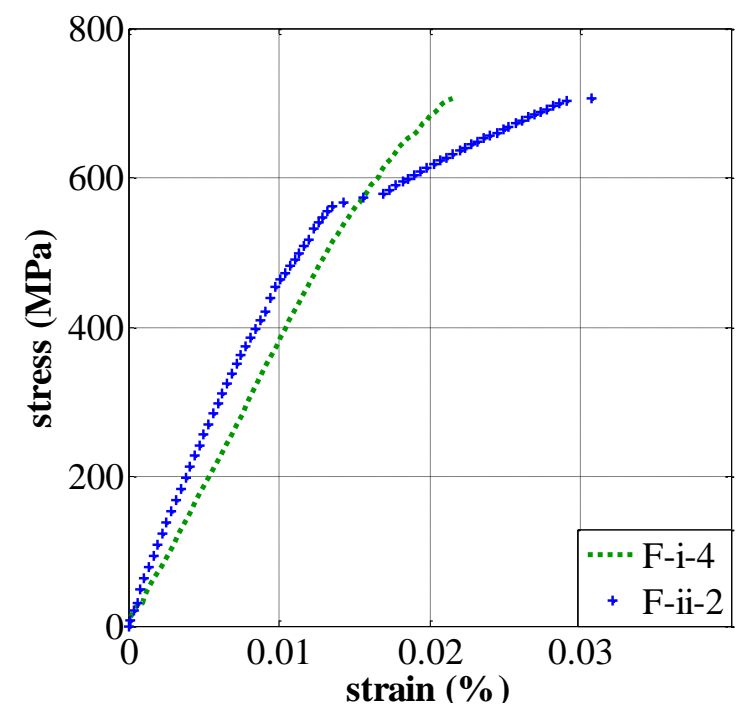

634

(c) Typical tests having multiple cores and various brace arrangements

635

636

Fig. 12. Stress-strain curves for composites having multiple cores 